\title{
Abordagens ao ponto cego da unidade de controle interno nos poderes municipais do Estado de Rondônia
}

\author{
Approaches to the blind point of the internal control unit in the \\ municipal powers of the State of Rondônia
}

\section{Gleice Carvalho de Lima Moreno}

Universidade Federal de Rondônia, Departamento de Ciências Contábeis.

gleice.cl11@gmail.com

Com Mestrado Acadêmico em Ciências Contábeis pela Universidade Federal de Pernambuco, leciona no Departamento de Ciências Contábeis da Universidade Federal de Rondônia, faz pesquisas na área de Contabilidade Ambiental, Contabilidade e Administração Pública, Políticas Públicas, Comunicação Empresarial e Gestão de Negócios.

\section{José Moreira da Silva Neto}

Universidade Federal de Rondônia, Departamento de Ciências Contábeis. msilva@unir.br

Doutorado em Engenharia de Produção pela Universidade Federal de Santa Catarina, Professor Titular da Universidade Federal de Rondôna,

\section{Luiz Carlos Miranda}

Universidade Federal de Pernambuco, Departamento de Ciências Contábeis. mirandaphd@gmail.com

Doutorado em Ph. D. Program In Agribusiness pela University of Illinois - System, Estados Unidos, Professor Titular da Universidade Federal de Pernambuco.

\section{Carlos da Silva Reis Junior}

Universidade Federal de Rondônia, Departamento de Ciências Contábeis. reisjunior40@gmail.com

Bacharel em Ciências Contábeis pela Universidade Federal de Rondônia.

\section{Fabio Ferreira da Silva}

Universidade Federal de Rondônia, Departamento de Auditoria

fabiofe@unir.br

Auditor Chefe - AUDIN da Universidade Federal de Rondônia, com Mestrado em Administração pela mesma Instituição.

\section{RESUMO}

Este estudo tem como objetivo evidenciar os pontos cegos nas abordagens: subordinação, atribuições, competências, contratação e qualificação dos servidores da Unidade de Controle 
Interno (UCI), com a perspectiva de restringi-los, e consequentemente, melhorar o exercício pleno do controle, fundamentado nos princípios da eficaz administração pública. Espera-se contribuir para a identificação de possíveis falhas originadas pela não restrição às atividades. A coleta de dados ocorreu em dez municípios do Estado de Rondônia, com consulta aos sites das prefeituras e câmaras municipais, visita a algumas unidades, além de solicitação por $e$-mail dos regulamentos legais criados para a institucionalização da UCI. Consecutivamente foram examinados esses regulamentos. Os resultados mostram que a UCI, no que se refere às abordagens evidenciadas, apresentam critérios vulneráveis para a prática do controle.

Palavras-chave: Unidade de Controle Interno; Abordagens ao ponto cego; Controle.

\section{ABSTRACT}

This study aims to highlight the blind spots in the approaches: subordination, assignments, skills, hiring and qualification of the Internal Control Unit (ICU) servers, with the prospect of restricting them, and consequently improving the full exercise of control, based on the principles of effective public administration. It is hoped to contribute to the identification of possible failures caused by non-restriction to activities. The data collection took place in ten municipalities of the State of Rondônia, with consultation to the sites of city halls and municipal councils, visits to some units, and e-mail solicitation of the legal regulations created for the institutionalization of the ICU. These regulations were subsequently examined. The results show that the ICU, with regard to the approaches shown, present vulnerable criteria for the practice of control.

Keywords: Internal Control Unit; Approaches to blind spot; Control.

\section{Introdução}

Apesar de a Lei 4320/64 já ter se posicionado em relação ao controle interno e externo no ambiente público, a implantação da Unidade de Controle Interno (UCI) só ocorreu a partir da Constituição Federal de 1988, tendo se fortalecido após a Lei Complementar 101/2000, que trata de normas de finanças públicas voltadas para a responsabilidade na gestão fiscal, assim como o uso de melhores práticas de governança corporativa. Entretanto, é perceptível que a implantação da Unidade de Controle Interno tem ocorrido de forma tardia e descompassada na maior parte dos municípios brasileiros, como consta em trabalho desenvolvido por Moreno e Miranda (2013), cuja amostra foi formada por 56 municípios abrangendo todas as regiões do Brasil.

O Sistema de Controle Interno (SCI) coordenado pela UCI de acordo com a Instrução Normativa 001/2001 tem a finalidade de avaliar a gestão dos administradores públicos, por meio da fiscalização contábil, financeira, orçamentária, operacional e patrimonial. Mesmo essa Instrução Normativa sendo aplicada no Poder Executivo Federal, seus parâmetros podem se estender aos Tribunais de Contas e aos poderes municipais, como base para a melhor estruturação e definição de regras direcionadas à Unidade de Controle Interno (UCI). Oliveira et al. (2013) afirmam "que o sistema de controle interno envolve todas as atividades e rotinas, 
de natureza contábil e administrativa, fazendo cumprir as políticas e diretrizes traçadas pela administração".

A Unidade de Controle Interno visa cooperar com a administração do órgão, acompanhando o cumprimento das normas, reduzindo a intensidade de fenômenos que possam acarretar o mau uso dos recursos públicos, promovendo o zelo, a guarda, a vigilância, o controle e o acompanhamento das atividades desenvolvidas nos órgãos públicos municipais.

As contas públicas sempre foram alvos de críticas, análises, discussões e dúvidas, que caracterizam as incertezas existentes no ambiente público. Essas incertezas têm sido comuns mesmo com a implantação das unidades de controle interno nos órgãos públicos municipais. Fatos que comprovem essa afirmativa são amplamente divulgados nos meios de comunicação em suas diversas extensões. Os casos de descontrole mais comuns estão relacionados ao uso indevido dos recursos públicos, que deveriam ser destinados à sociedade através de serviços que promovessem um maior bem-estar social.

A UCI, quando bem aplicada para acompanhar as atividades desenvolvidas em um órgão público, torna-se um mecanismo de gestão que promove a defesa contra as irregularidades, causadas de forma intencional (fraude é intencional) ou não (a impropriedade não intencional é erro). Contudo, a concretização de forma eficaz desse sistema ocorrerá à medida que for criada uma estrutura firmada nas normas legais e sustentada por intermédio de cursos de aperfeiçoamento de pessoal que orientem a lidar com as atividades de controle. Neste contexto, o acompanhamento, as consultas, a avaliação e as recomendações geradas pela auditoria interna são atividades importantes para melhorar a boa estrutura de controle, possibilitando assim reduzir as probabilidades de danos ao erário público.

Dessa forma, as pessoas que atuam no ambiente público podem ser responsáveis ou corresponsáveis pelos erros que forem cometidos no desenrolar das atividades. Assim, é importante e necessário que os órgãos públicos determinem por meio de regulamentos legais a forma de contratação, a subordinação, as atribuições e as competências dos servidores que atuam na UCI, especificamente, bem como o perfil caracterizado pela unidade, considerando títulos (graus acadêmicos) e cursos de aperfeiçoamento que se relacionem às atividades do SCI.

Diante disso, elaborou-se este estudo com o propósito de evidenciar os pontos cegos nas abordagens: subordinação, atribuições, competências, contratação e qualificação dos servidores da UCI, com a perspectiva de restringi-los, e consequentemente, melhorar o exercício pleno do controle, fundamentado nos princípios da eficaz administração pública, junto aos Poderes 
Públicos Municipais do Estado de Rondônia, tomando por base o Executivo e o Legislativo Municipal. Dessa forma, a pesquisa busca respostas para a seguinte questão: Quais são os principais pontos cegos que restringem o desempenho de pessoas na UCI dos municípios de Rondônia?

Esta pesquisa é importante por apresentar aos pesquisadores e estudantes do ambiente público se as possíveis falhas percebidas e tão comuns nos Poderes Executivos e Legislativos Municipais são provenientes dos regulamentos legais que norteiam a nomeação de pessoal sem os limites adequados para a UCI nos Municípios Rondonienses. Quanto ao ponto cego da UCI de acordo com Silva Neto (2016), componente da banca, refere-se à prática interna que carece de correção ou ação de desenvolvimento para uma nova cultura ou prática, partindo desse ponto cego uma oportunidade de melhoria.

\section{Referencial Teórico}

\subsection{Unidade de Controle Interno nos Poderes Municipais}

O controle é um procedimento adotado por diversos grupos, sejam empresariais ou pessoais, com o propósito de avaliar se as metas estão sendo cumpridas, se os objetivos estão sendo alcançados e se os recursos disponíveis estão sendo bem utilizados. Em sua composição temos os recursos (máquinas e equipamentos, estrutura predial, documentos, e outros bens), que precisam ser controlados, e as pessoas (seres humanos, cidadãos com direitos e deveres determinados na esfera legal) que devem assumir o controle, como também serem controladas.

As pessoas são consideradas peças-chave para a manutenção e o bom funcionamento do controle. Para isso, é necessário comprometimento por parte da equipe, treinamento e capacitação, além dos elementos necessários para a execução das atividades. Em outras situações, as pessoas quando não bem orientadas, ao invés de proteger os recursos públicos, podem utilizá-los de forma negligente, acarretando o seu mau uso. Complementando o parágrafo anterior, Morelo (2011) informa que as falhas nos controles estabelecidos no ambiente público podem ocorrer quando os servidores não absorvem bem as orientações ou eles cometem erros por descuido na execução das atividades. Ele também informa que nos casos de pessoal temporário, constantes alterações nos procedimentos adotados, bem como alterações nos sistemas processuais, também podem contribuir para o surgimento de novos incidentes, gerando o uso excessivo do erário. 
De acordo com Andrade (2008), a ausência de um bom controle interno acarreta riscos; um deles seria o de assumir despesas sem recursos disponíveis. Logo, é importante que as atividades estejam em conformidade com a LC 101/2000, conhecida também como Lei de Responsabilidade Fiscal, sancionada com o propósito de ajustar as finanças públicas aos modernos conceitos de gestão, fazendo uso das práticas de Governança Corporativa, tais como a transparência e a prestação de contas, e coibir atos ilegais com punições severas, norteando as ações para o bom uso dos recursos públicos.

Moreno e Miranda (2013) apontam como sendo ainda embrionária a implantação das unidades de controle interno nas entidades públicas, afirmando com propriedade os casos dos Poderes Executivo e Legislativo Municipais. O resultado do estudo mostrou que os Poderes Municipais com orientação dos Tribunais de Contas estão criando regulamentos legais, mas ainda em desacordo com as melhores práticas evidenciadas pela legislação, normas técnicas e bases teóricas. Corroborando com esse estudo, Lima et al. (2014) reconheceram o importante papel dos Tribunais de Contas Municipais e Estaduais (TCs) brasileiros, no que diz respeito à institucionalização do Sistema de Controle Interno, mas identificaram que os atos institucionais dos TCs deixaram de incluir informações que poderiam contribuir para a melhor implantação dessa Unidade.

Além disso, há a interferência do fator cultural no âmbito público, que geralmente provoca resultados ineficazes no atingimento de metas e objetivos traçados pela não aceitabilidade às mudanças impostas pelos órgãos de controle, o que ocasiona deficiência nos processos e atraso na solução dos erros e falhas detectadas (CHU e WOOD, 2008). Dessa forma, para a efetiva implantação do sistema de controle interno nos órgãos públicos municipais, é necessário coibir os empecilhos mais recorrentes e com eles uma série de procedimentos que inibem a implantação de novas normas. Assim, precisa-se cultivar de forma consistente o controle entre os usuários do serviço público dentro de suas limitações, permitindo que os recursos públicos sejam bem utilizados seguindo as instruções do Código de Ética do Servidor Público Municipal, criado por cada município, para manter a ordem nos serviços públicos.

Diante das discussões apresentadas, esta pesquisa se justifica pela busca eminente do controle nas contas públicas, pela devida atuação dos servidores à frente da Unidade de Controle Interno e consequentemente pela correta aplicação dos recursos. 


\subsection{Abordagens ao ponto cego da UCI}

As abordagens selecionadas para evidenciar o ponto cego da UCI, foram aquelas que restringem as atividades desenvolvidas pelos servidores dispostos nessa unidade e que possibilitam o pleno exercício do controle.

Dentre essas abordagens, destacam-se nesse estudo a: Subordinação, Atribuições, Competências, Contratação e Qualificação, que foram selecionadas em virtude de determinar as limitações e o perfil mais adequado que o servidor precisa ter para a melhor atuação na UCI que coordena o SCI.

\begin{tabular}{|c|c|c|}
\hline ABORDAGENS & INTERPRETAÇÃO & $\begin{array}{c}\text { BASES TEÓRICAS E } \\
\text { LEGAIS }\end{array}$ \\
\hline Subordinação & $\begin{array}{l}\text { Determina o grau de independência dos servidores } \\
\text { atuantes na UCI de um órgão público, para o seguro } \\
\text { desenvolvimento do trabalho, constante em regulamento } \\
\text { legal que apresenta as diretrizes para a unidade de } \\
\text { controle. }\end{array}$ & IN 001/2001 da SFC/MF \\
\hline Atribuições & $\begin{array}{l}\text { As atribuições ficam a cargo do Controlador Interno } \\
\text { (bacharel ou técnico contábil, entre outras áreas), podendo } \\
\text { ser ou não do quadro efetivo, atuando em conjunto com o } \\
\text { setor contábil. }\end{array}$ & Oliveira et al. (2013) \\
\hline Competências & $\begin{array}{l}\text { As competências estão diretamente associadas ao } \\
\text { conhecimento, as habilidades e aos valores que o } \\
\text { servidor atuante nessa unidade precisa ter, para o bom } \\
\text { desempenho da função. }\end{array}$ & Carneiro e Silva Neto (2015) \\
\hline Contratação & Formas de contratação destacadas logo abaixo. & Lima e Miranda (2012) \\
\hline Qualificação & $\begin{array}{l}\text { A sua composição deve ser formada por servidores com } \\
\text { níveis de formação superior de acordo com o Princípio da } \\
\text { Qualificação Adequada. }\end{array}$ & DN 002/2016/TCE-RO \\
\hline
\end{tabular}

Fonte: Adaptado de Lima e Miranda (2012).

Destaca-se a seguir as formas de contratação, consideradas fator crítico para o bom andamento das atividades de controle realizadas pela UCI. De acordo com Lima e Miranda (2012) existem as formas de contratação que devem ser definidas em lei, garantindo ou não a independência na execução do controle interno. 
Quadro 2. Formas de contratação

\begin{tabular}{|c|c|c|c|}
\hline ABREV. & CONTRATO & DESCRIÇÃO & $\begin{array}{c}\text { GRAU DE } \\
\text { INDEPENDÊNCIA }\end{array}$ \\
\hline $\mathrm{E}$ & Efetivo & $\begin{array}{c}\text { Contratado por meio de } \\
\text { concurso específico } \\
\text { para o SCI. }\end{array}$ & $\begin{array}{l}\text { Assume suas } \\
\text { atribuições com } \\
\text { independência }\end{array}$ \\
\hline CER & $\begin{array}{l}\text { Comissionado } \\
\text { externo com } \\
\text { remuneração }\end{array}$ & $\begin{array}{l}\text { Contrato de caráter } \\
\text { provisório, destinando- } \\
\text { se as atribuições de } \\
\text { chefia. }\end{array}$ & $\begin{array}{l}\text { Tem independência em } \\
\text { relação aos que estão } \\
\text { abaixo de quem o } \\
\text { contratou }\end{array}$ \\
\hline CEG & $\begin{array}{l}\text { Comissionado } \\
\text { efetivo com } \\
\text { gratificação }\end{array}$ & $\begin{array}{l}\text { Contratado por meio de } \\
\text { concurso público com } \\
\text { gratificação, por } \\
\text { executar exercício de } \\
\text { natureza extraordinária. }\end{array}$ & $\begin{array}{l}\text { Não dispõe de total } \\
\text { independência, pois } \\
\text { pode voltar ao cargo } \\
\text { original a qualquer } \\
\text { tempo }\end{array}$ \\
\hline CES & $\begin{array}{l}\text { Comissionado } \\
\text { efetivo sem } \\
\text { gratificação }\end{array}$ & $\begin{array}{l}\text { Contratado por meio de } \\
\text { concurso público, } \\
\text { colocado a disposição } \\
\text { em outras áreas. }\end{array}$ & $\begin{array}{l}\text { Menos independente de } \\
\text { todas as alternativas de } \\
\text { contratação }\end{array}$ \\
\hline
\end{tabular}

Fonte: Lima e Miranda (2012).

Dependendo da forma de contratação que constar nos regulamentos legais dos Poderes Públicos Municipais (Executivo e Legislativo), espera-se que a autonomia e a independência dos servidores sejam garantidas, para a execução completa do controle nos órgãos.

\subsection{Panorama de fraudes na esfera municipal do Brasil: Alguns casos}

Com o passar dos anos e com o aumento de irregularidades no ambiente público municipal, nota-se a extrema necessidade da aplicação da auditoria forense ou investigativa, cujo objetivo é revisar o sistema de controle interno e por meio dessa investigação identificar possíveis erros, desvios e fraudes que comprometam as atividades públicas (SILVA, 2008). Destaca-se nesta seção alguns casos corriqueiros, que tem como principais atores os servidores públicos.

Em consulta realizada à web site do Tribunal de Contas do Estado do Rio Grande do Sul (TCE-RS) em 20 de janeiro de 2016, foi visto que o ex-gestor da Câmara de Vereadores de Tramandaí, no exercício de 2012, teve suas contas regulares com ressalva, sendo definida a devolução aos cofres públicos da quantia usada para o pagamento irregular de diárias aos servidores em viagem. Observa-se nesse caso a falta de controle no acompanhamento das atividades exercidas e na ausência do controle de frequência dos servidores tão comum nos poderes municipais. 
Em um outro caso, visto no noticiário da TV Globo em 14 de janeiro de 2016, o Grupo de Atuação Especial de Combate às Organizações Criminosas do Ministério Público Estadual do Maranhão investigou junto ao Ministério Público Federal (MPF) e à Polícia Federal (PF) o envolvimento da Prefeita do Município de Bom Jardim no desvio de recursos públicos, que deveriam ser destinados à sociedade por meio de prestação de serviços, foram desviados por intermédio de fraudes em licitações, desvio de verbas e transferências bancárias irregulares. Nesse caso, constata-se a falha nos controles dos recursos públicos ou por despreparo ou pelo uso de má fé dos recursos humanos dos órgãos municipais. Vale ressaltar, que a obtenção de um controle mais efetivo nesses órgãos será possível, de acordo com Carneiro Junior e Oliveira (2012), à medida que as pessoas passem a ser monitoradas e dessa forma se conscientizem de suas responsabilidades, cumprindo o seu papel de forma eficaz.

Uma outra situação, não menos assustadora que as demais, exibida também no noticiário da TV Globo em 12 de fevereiro de 2016, mostrou o desvio de recursos com contratos de obras municipais falsos e o uso de "laranja" em contratação fraudulenta no município de Itapemirim/ES (MPE - ES), fazendo uso de contratos ilícitos, superfaturamento de obras, aluguéis de carros e consultorias fantasmas. Nota-se que para manter os cargos no ambiente público há a cumplicidade entre os servidores, que por receio, ou mesmo pelo envolvimento na ação ilícita, mantém sigilo de atos corruptíveis.

Moreno e Miranda (2013) apontam que mesmo havendo a legislação que normatiza a instituição do sistema de controle interno nos Poderes Municipais, há muitas falhas e descontroles que influenciam o andamento das atividades, gerando irregularidades nesse ambiente. Dessa forma, as ações deixam de ser cumpridas porque os interesses pessoais dos gestores públicos estão, na maior parte dos casos, em primeiro lugar, descumprindo aos princípios da administração pública que regem sobre o atendimento aos interesses coletivos, a ética e a obediência à lei: impessoalidade, moralidade e legalidade.

Diante dos casos mencionados, constata-se que as fragilidades no ambiente público são provenientes das pessoas e da falta de controle sobre essas pessoas, devendo haver um acompanhamento severo desses profissionais e do cumprimento de suas atividades de acordo com as determinações legais. 


\section{Metodologia}

Tomando por base os casos apresentados e discutidos na seção anterior, este trabalho busca evidenciar os pontos cegos nas abordagens: subordinação, atribuições, competências, contratação e qualificação dos servidores da Unidade de Controle Interno (UCI), com a perspectiva de restringi-los, e consequentemente, melhorar o exercício pleno do controle, fundamentado nos princípios da eficaz administração pública. A orientação dada pelo Tribunal de Contas do Estado, por meio da Decisão Normativa N. 002/2016/TCE-RO, estabelece as regras gerais para a implantação e operacionalização do sistema de controle interno.

O objeto deste estudo se centraliza nos critérios definidos em lei para a institucionalização do sistema de controle interno, dando ênfase às abordagens que restringem as atividades dos servidores, vinculados ao órgão de controle municipal. O trabalho teve como universo os 52 municípios do Estado de Rondônia, classificados entre pequeno, médio e grande porte. Contudo, a amostra foi formada pelos 10 maiores municípios em porte populacional, como consta no Quadro 3.

Quadro 3. Classificação da amostra por categorias

\begin{tabular}{|l|r|r|r|}
\hline \multirow{2}{*}{ Categorias } & Rondônia & Amostra & \multirow{2}{*}{$\%$} \\
\cline { 2 - 3 } & $\mathbf{N}$ & $\mathbf{N}$ & \multicolumn{1}{c|}{} \\
\hline Pequeno Porte I & 35 & 0 & $0 \%$ \\
\hline Pequeno Porte II & 10 & 3 & $30 \%$ \\
\hline Médio Porte & 5 & 5 & $50 \%$ \\
\hline Grande Porte & 2 & 2 & $20 \%$ \\
\hline Metrópole & 0 & 0 & $0 \%$ \\
\hline Total & 52 & 10 & $100 \%$ \\
\hline
\end{tabular}

Fonte: Elaboração própria.

Os procedimentos empregados para a coleta de dados foram os apresentados a seguir:

- Utilização de navegadores para busca dos regulamentos legais;

- Visita aos Poderes Públicos Municipais ou solicitação por e-mail, para os casos em que os regulamentos não foram identificados na internet; e

- $\quad$ Exame da legislação que trata da implantação da Unidade de Controle Interno.

Os autores desta pesquisa trabalharam com uma amostra previamente definida abrangendo os 10 maiores municípios em porte populacional do Estado de Rondônia, conforme apresentado no Quadro 4. 
Quadro 4. Representatividade da amostra

\begin{tabular}{|c|c|c|c|c|}
\hline $\mathbf{N}^{\circ}$ & Municípios & Abreviação & Habitantes & $\%$ \\
\hline 1. & Porto Velho & PVH & 435.732 & $43 \%$ \\
\hline 2. & Ji-Paraná & JPA & 117.363 & $12 \%$ \\
\hline 3. & Ariquemes & $\mathrm{ARQ}$ & 91.570 & $9 \%$ \\
\hline 4. & Cacoal & CAC & 78.958 & $8 \%$ \\
\hline 5. & Vilhena & VLH & 77.937 & $8 \%$ \\
\hline 6. & Jarú & JAR & 51.883 & $5 \%$ \\
\hline 7. & Rolim de Moura & RMO & 50.899 & $5 \%$ \\
\hline 8. & Guajará-Mirim & GJM & 41.933 & $4 \%$ \\
\hline 9. & Ouro Preto & OPO & 37.701 & $4 \%$ \\
\hline 10. & Pimenta Bueno & PBU & 33.981 & $3 \%$ \\
\hline \multicolumn{3}{|c|}{ Total } & 1.017 .957 & $100 \%$ \\
\hline
\end{tabular}

Fonte: Elaboração própria.

As abordagens evidenciadas foram as descritas no Quadro 5.

Quadro 5. Abordagens analisadas da UCI

\begin{tabular}{|c|c|c|}
\hline N. & Pré-Requisitos & $\begin{array}{l}\text { Recursos } \\
\text { Humanos }\end{array}$ \\
\hline 1. & Subordinação & \multirow{5}{*}{$\begin{array}{c}\text { Abordagens ao } \\
\text { ponto cego da } \\
\mathrm{UCl}\end{array}$} \\
\hline 2. & Atribuições & \\
\hline 3. & Competências & \\
\hline 4. & Contratação & \\
\hline 5. & Qualificação & \\
\hline
\end{tabular}

Fonte: Adaptado de Lima e Miranda (2012).

Os resultados desta pesquisa tendem a apresentar a origem das fragilidades do sistema de controle interno na esfera municipal decorrentes das abordagens ao ponto cego da UCI. A identificação desses fatores permitirá compreender o porquê do descontrole no ambiente público municipal e do não acompanhamento da evolução tecnológica, uma vez que o avanço tecnológico tende a resolver as questões burocráticas em menor tempo e com maior segurança. No entanto, Davis e Blaschek (2006) dizem que, à medida que se tem mais tecnologia, os setores que estão na maior escala hierárquica tendem a obter mais poder, ficando o controle à mercê do comportamento ético de seus componentes. 


\section{Análise dos Resultados}

A seleção dos regulamentos que trata da UCI ocorreu durante o ano de 2016 nos Poderes Municipais da amostra definida para análise, que foi identificada conforme demonstrado no Quadro 6 abaixo.

Quadro 6. Acesso aos regulamentos legais dos Poderes Públicos Municipais

\begin{tabular}{|c|c|c|c|c|c|c|c|c|c|c|c|}
\hline Órgãos e Municípios & Pvh & Jpa & Arq & Cac & Vlh & Jar & Rmo & Gjm & Opo & Pbu & Total \\
\hline Executivo & & & 息 & & & $\theta$ & & & & & 10 \\
\hline Legislativo & & & & & & & & & & & 10 \\
\hline
\end{tabular}

Fonte: Elaboração própria.

Nota-se que foi necessário visitar quatro municípios, com a perspectiva do recebimento dos regulamentos legais. Apenas dois municípios apresentaram regulamentos disponíveis nos portais de acesso, atendendo ao Tribunal de Contas do Estado de Rondônia, que já tomou posicionamento em relação à criação da UCI nos Poderes Executivo e Legislativo Municipais, estabelecendo na Decisão Normativa $n^{\circ}$ 002/2016/TCE-RO e em decisões anteriores, diretrizes para implementação e operacionalização do sistema de controle interno. Dentre as orientações, estão dispostas 17 atribuições delegadas para a área, oito competências que determinam as habilidades, os conhecimentos e valores que os profissionais atuantes na área precisam ter e a independência no desempenho das funções, sendo esta submissa apenas ao Chefe do Poder Municipal. Quanto à qualificação dos profissionais, é especificado o nível, mas não a área de conhecimento que os candidatos precisam ter, ficando a critério de cada Poder. O TCE/RO aconselha ainda que a contratação de pessoal para a UCI deve ocorrer realocando servidores efetivos para essa unidade. De acordo com Lima e Miranda (2012), os Tribunais de Contas responsáveis em auxiliar o Poder Legislativo nas atividades de Controle Externo em todo o Brasil têm regulamentado por meio de atos legais a forma de atuação do Sistema de Controle Interno nos Poderes Municipais.

Os municípios, na tentativa de se adequar às exigências do Tribunal de Contas do Estado de Rondônia, têm criado regulamentos ou já dispõem de regulamentos antigos caracterizados em sua maior parte como lei, prescritas pelo Poder Legislativo Municipal, como apresentado na Figura 1. 
Figura 1. Regulamentos legais gerados pelos municípios para a institucionalização da UCI.

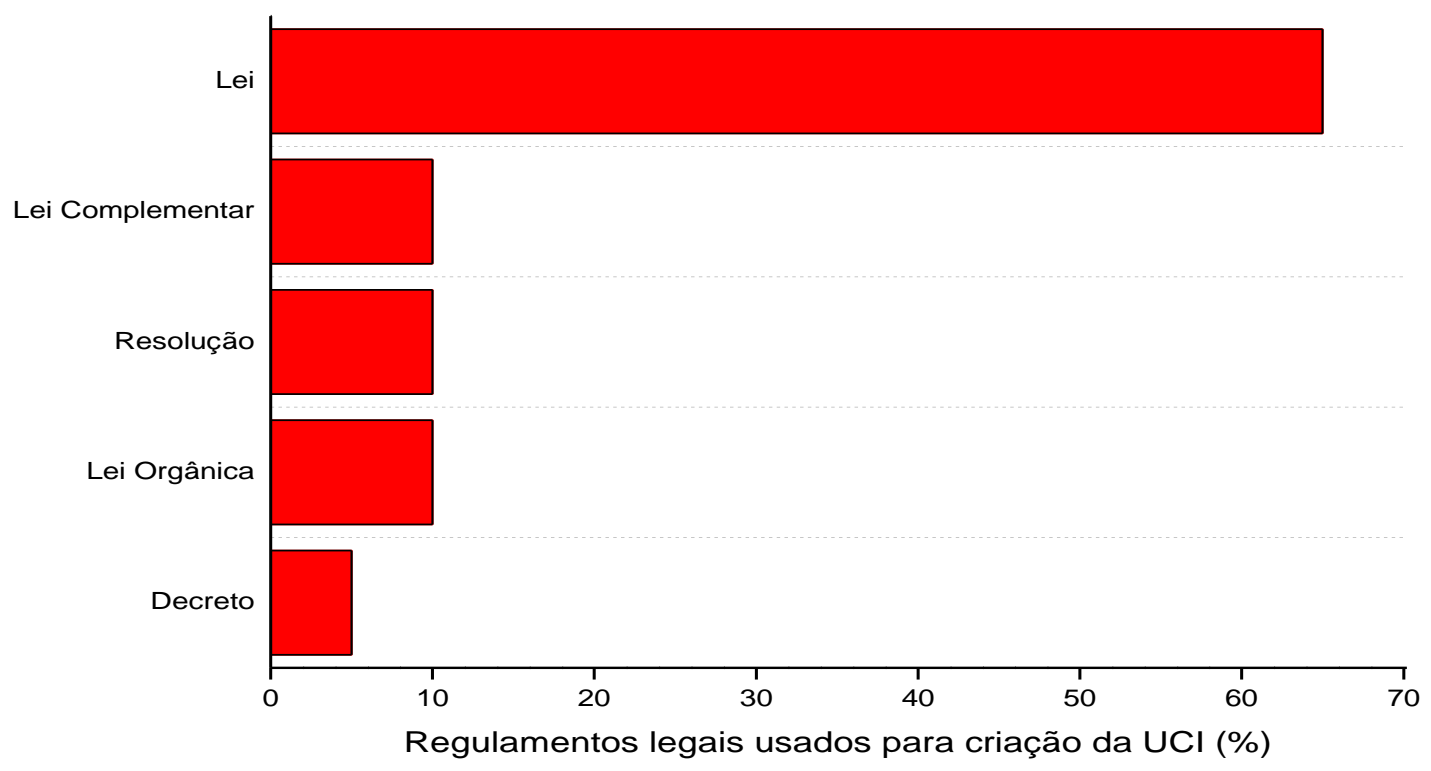

Fonte: Elaboração própria.

A Figura 1 mostra o gráfico que resume os tipos de regulamentos mais comuns para a amostra em análise. Mesmo que a maioria dos órgãos tenha criado lei que trata do controle interno no âmbito municipal, apenas 5 (cinco) poderes executivos e 2 (dois) legislativos realizaram a institucionalização do SCI. Destacam-se os Municípios de Guajará-Mirim e Ouro Preto do Oeste (Poderes Executivo e Legislativo), e Jarú, Vilhena e Porto Velho (Poder Executivo). Para os últimos casos houve a criação da Controladoria Geral do Município, que caso tenha sido criada para suprir a necessidade de manutenção do controle interno nos poderes, acaba sendo contrário ao que determina a Constituição Federal de 1988, em seu Art. 70 quando se refere ao SCI:

Art. 70 A fiscalização contábil, financeira, orçamentária, operacional e patrimonial da União e das entidades da administração direta e indireta, quanto à legalidade, legitimidade, economicidade, aplicação das subvenções e renúncia de receitas, será exercida pelo Congresso Nacional, mediante controle externo, e pelo sistema de controle interno de cada Poder.

Dessa forma, é de responsabilidade de cada poder a criação de regulamentos legais para a devida institucionalização do Sistema de Controle Interno, garantindo o acompanhamento seguro das operações. Para os demais casos, as leis que tratavam do Sistema de Controle Interno tinham relação com: a Estrutura Político Administrativa; a Estrutura Organizacional; e o Plano de Cargos e Salários. 
No que se refere à subordinação da Unidade nos Poderes Executivo e Legislativo Municipal, apurou-se a seguinte situação constante no Quadro 5 que trata de uma das abordagens analisadas da UCI:

Quadro 7. A subordinação da UCI nos Poderes Municipais

\begin{tabular}{|c|c|c|c|c|c|c|}
\hline \multirow{2}{*}{ Subordinação } & \multicolumn{3}{|c|}{ Poderes Municipais } & \multicolumn{2}{|c|}{ Total } \\
\cline { 2 - 6 } & \multicolumn{2}{|c|}{ Executivo } & \multicolumn{2}{|c|}{ Legislativo } & \multicolumn{2}{c|}{} \\
\cline { 2 - 6 } & $\mathbf{N}$ & $\%$ & $\mathbf{N}$ & $\%$ & $\mathbf{N}$ & $\%$ \\
\hline Chefe do Poder & 3 & $30 \%$ & 5 & $50 \%$ & 8 & $40 \%$ \\
\hline Outros Setores & 0 & $0 \%$ & 0 & $0 \%$ & 0 & $0 \%$ \\
\hline Sem informação & 7 & $70 \%$ & 5 & $50 \%$ & 12 & $60 \%$ \\
\hline Total & 10 & $100 \%$ & 10 & $100 \%$ & 20 & $100 \%$ \\
\hline
\end{tabular}

Fonte: Adaptado de Lima e Miranda (2012).

Sabendo-se que os profissionais atuantes na UCI precisam de independência e autonomia para desenvolverem suas atividades, o justo é que essa unidade esteja subordinada apenas ao Chefe do órgão, evitando assim possíveis manipulações na apuração das análises e intervenção no desenvolver das atividades, impedindo que os atos ilícitos sejam descobertos com maior tempestividade, ou mesmo possíveis retaliações geradas pelo descontentamento de servidores após o resultado de análises que apontam prováveis responsáveis por negligência administrativa. Conferindo a tabulação dos dados, verificou-se que a maior parte dos órgãos ainda não definiu a submissão da UCI e isso reflete negativamente no desempenho das atividades profissionais, porque os servidores tornam-se incapazes de resolver problemas de sua competência.

Posteriormente, tratou-se das atribuições que foram mais consideradas nos regulamentos investigados, avaliando se estão de acordo com a Decisão Normativa $\mathrm{n}^{\circ}$ 002/2016/TCE-RO. Os dados estão apresentados na Figura 2. 
Figura 2. Atribuições do TCE/RO mais citadas nos regulamentos.

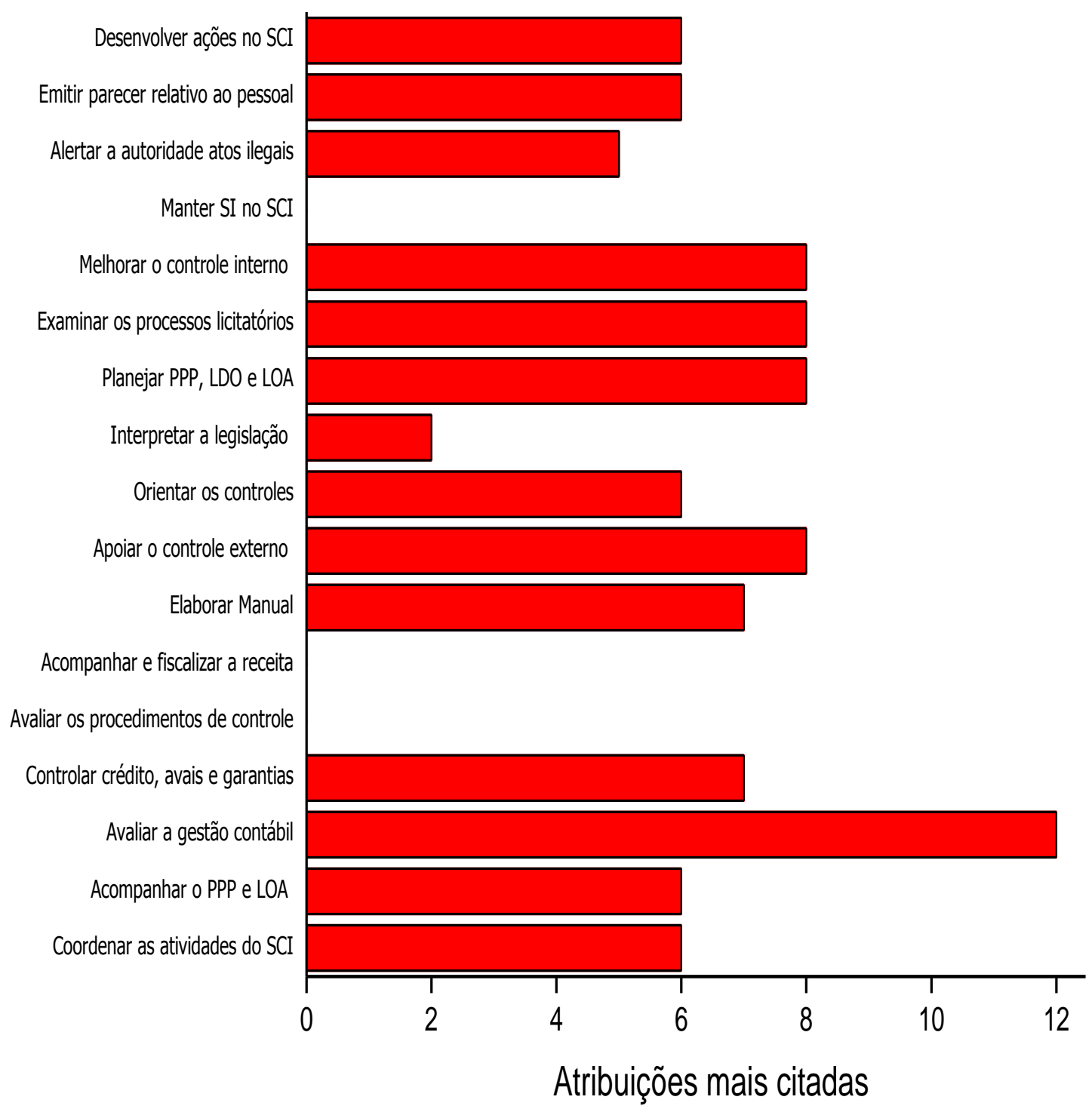

Fonte: Elaboração própria.

Como percebido, nem todas as atribuições foram contempladas nos regulamentos, fragilizando a execução das atividades na UCI.

Em seguida, verificou-se as competências determinadas para os atuantes na UCI, que se diferencia das atribuições, uma vez que as competências têm relação com a capacidade que um indivíduo tem de resolver os problemas corriqueiros em uma determinada área, enquanto que as atribuições são as atividades imputadas a alguém em um ambiente de trabalho. Na Figura abaixo temos as competências orientadas pelo TCE/RO. 
Figura 3. Competências do TCE/RO mais citadas nos regulamentos.

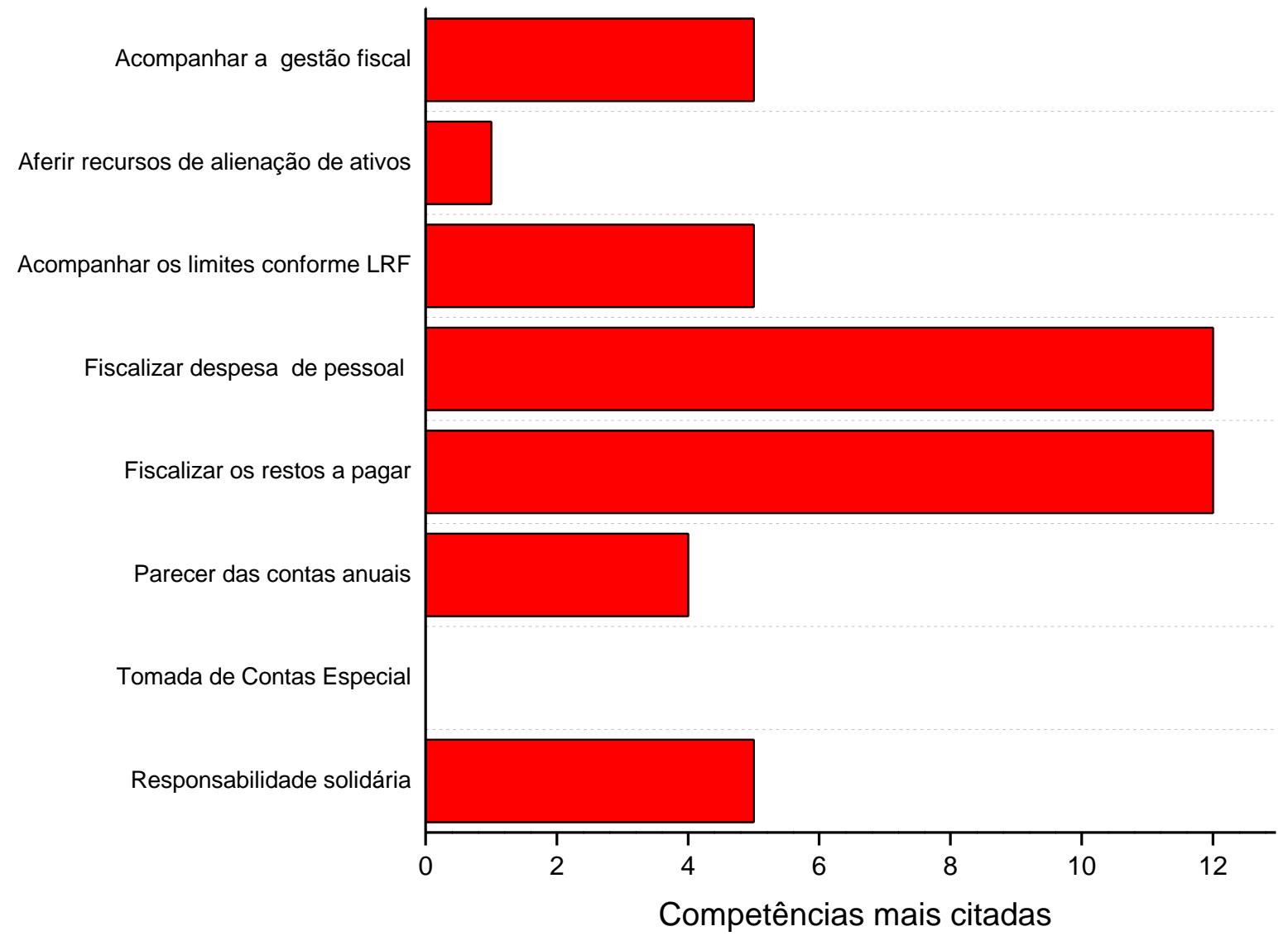

Fonte: Elaboração própria.

Como se viu, a Figura 3 mostra o gráfico que considera as competências mais citadas nos regulamentos legais dos Poderes Municipais e nenhuma delas alcançou a totalidade de órgãos que faz parte da amostra analisada.

Ficou perceptível que, independentemente de os Poderes Municipais possuírem autonomia político-administrativa e financeira em relação à administração do município (obras públicas, prestação de serviços públicos, contratação de pessoal, criação de leis, deliberação de tributos, entre outros), é importante a atuação do Tribunal de Contas no que diz respeito à normatização e ao aprimoramento do SCI, operante em cada um dos poderes, uma vez que cabe aos Tribunais auxiliar aos demais órgãos e acompanhar o cumprimento do controle interno, efetivando assim o controle externo (KLERING et al., 2011).

Como os poderes são independentes, eles têm autonomia para atribuir características ou não na contratação de pessoal. Esse último caso acarreta problemas originados pelas pessoas contratadas e caracterizadas como: mal instruídas, com pouca qualificação, sem perfil adequado 
para a área de atuação, indicadas sem critério de seleção, e outros. Situação essa que torna o ambiente público municipal extremamente fragilizado, possibilitando a vastidão da corrupção.

Neste contexto, depara-se com as formas de contratação, que de acordo com Lima et al. (2014) é considerado um fator que merece atenção, porque os servidores temporários (comissionados), além de gerar gastos com treinamento e aperfeiçoamento de pessoal de forma contínua, por haver mudanças constantes, não promove a responsabilização dos atos.

O Quadro 8 apresenta como os órgãos analisados efetivam a contratação de pessoal e se atendem as orientações do TCE/RO.

Quadro 8. Formas de contratação de pessoal para a UCI

\begin{tabular}{|c|c|c|c|c|c|c|}
\hline \multirow{3}{*}{ Contratação } & \multicolumn{4}{|c|}{ Poderes Municipais } & \multirow{2}{*}{\multicolumn{2}{|c|}{ Total }} \\
\hline & \multicolumn{2}{|c|}{ Executivo } & \multicolumn{2}{|c|}{ Legislativo } & & \\
\hline & $\mathbf{N}$ & $\%$ & $\mathbf{N}$ & $\%$ & $\mathbf{N}$ & $\%$ \\
\hline Efetivo & 3 & $30 \%$ & 2 & $20 \%$ & 5 & $25 \%$ \\
\hline Comissionado & & & & & & \\
\hline Externo com & & & & & & \\
\hline Remuneração & 4 & $40 \%$ & 3 & $30 \%$ & 7 & $35 \%$ \\
\hline Comissionado & & & & & & \\
\hline Efetivo com & & & & & & \\
\hline Gratificação & 1 & $10 \%$ & 0 & $0 \%$ & 1 & $5 \%$ \\
\hline Comissionado & & & & & & \\
\hline Efetivo Sem & & & & & & \\
\hline Gratificação & 0 & $0 \%$ & 0 & $0 \%$ & 0 & $0 \%$ \\
\hline Sem informação & 2 & $20 \%$ & 5 & $50 \%$ & 7 & $35 \%$ \\
\hline Total & 10 & $100 \%$ & 10 & $100 \%$ & 20 & $100 \%$ \\
\hline
\end{tabular}

Fonte: Adaptado de Lima e Miranda (2012).

Conforme observado, a minoria dos poderes segue as orientações do TCE/RO, que determina a realocação de servidores efetivos para a UCI. A não disponibilização de informação nos regulamentos legais permite que o órgão público faça a contratação da maneira que melhor lhe convém, tornando vulnerável assim a execução das atividades desenvolvidas nessa unidade, pela provável contratação de pessoal despreparado.

Quanto à qualificação, outro fator importante no que concerne às abordagens evidenciadas, está associado à perícia que o pessoal da UCI precisa ter para analisar o cumprimento das determinações legais, conferir se o andamento das atividades está sendo executado de forma eficaz e se a prestação de serviço à sociedade está sendo realizada de forma eficiente, fazendo o melhor uso dos recursos que têm à disposição. A Decisão Normativa n. 002/2016/TCE (TCE/RO) determina que os servidores efetivos da UCI devem ter níveis superiores com qualificação adequada para a área, mas não detalhou quais os cursos mais 
convenientes, deixando a critério dos poderes. Observa-se no Quadro 9 a constatação do que se obteve com a tabulação dos dados.

Quadro 9. Qualificação de pessoal para a UCI

\begin{tabular}{|c|c|c|c|c|c|c|}
\hline \multirow{3}{*}{ Qualificação } & \multicolumn{4}{|c|}{ Poderes Municipais } & \multirow{2}{*}{\multicolumn{2}{|c|}{ Total }} \\
\hline & \multicolumn{2}{|c|}{ Executivo } & \multicolumn{2}{|c|}{ Legislativo } & & \\
\hline & $\mathbf{N}$ & $\%$ & $\mathbf{N}$ & $\%$ & $\mathbf{N}$ & $\%$ \\
\hline $\begin{array}{l}\text { Ciências Contábeis } \\
\text { Administracão, } \\
\text { Ciências Jurídicas } \\
\text { ou Economia }\end{array}$ & 3 & $30 \%$ & 3 & $30 \%$ & 6 & $30 \%$ \\
\hline $\begin{array}{l}\text { Administração } \\
\text { pública, de Empresa } \\
\text { ou C. Contábeis }\end{array}$ & 1 & $10 \%$ & 0 & $0 \%$ & 1 & $5 \%$ \\
\hline $\begin{array}{l}\text { C. Jurídicas, } \\
\text { Administração ou C. } \\
\text { Contábeis }\end{array}$ & 0 & $0 \%$ & 1 & $10 \%$ & 1 & $5 \%$ \\
\hline $\begin{array}{l}\text { Economia, C. } \\
\text { Jurídicas ou } \\
\text { Administração }\end{array}$ & 1 & $10 \%$ & 0 & $0 \%$ & 1 & $5 \%$ \\
\hline C. Contábeis & 1 & $10 \%$ & 0 & $0 \%$ & 1 & $5 \%$ \\
\hline $\begin{array}{l}\text { Engenharia, C. } \\
\text { Jurídicas, C. } \\
\text { Contábeis, } \\
\text { Economia ou } \\
\text { Administração }\end{array}$ & 1 & $10 \%$ & 0 & $0 \%$ & 1 & $5 \%$ \\
\hline Sem informação & 3 & $30 \%$ & 6 & $60 \%$ & 9 & $45 \%$ \\
\hline Total & 10 & $100 \%$ & 10 & $100 \%$ & 20 & $100 \%$ \\
\hline
\end{tabular}

Fonte: Adaptado de Lima e Miranda (2012).

Dos 20 (vinte) poderes consultados, notou-se a determinação de qualificação específica para 55\% dos órgãos. Isso reflete, apesar de não constar nas orientações do TCE/RO as áreas específicas e mais adequadas, a preocupação da gestão pública quanto ao dinamismo e ao bom desempenho dos servidores envolvidos na UCI.

Logo, conclui-se que mesmo havendo um acompanhamento mais rigoroso por parte dos Tribunais de Contas, ainda assim, a UCI apresenta abordagens vulneráveis para a execução efetiva do controle, decorrentes do perfil inadequado de servidores e da ineficiência das diretrizes firmadas nos regulamentos legais. 


\section{Conclusões}

Por fim, pode-se concluir que às abordagens evidenciadas, apresentam critérios vulneráveis para a prática do controle não restringindo o desempenho dos servidores. As abordagens definidas em atos normativos foram ineficientes por apresentar incompletude nas diretrizes firmadas nos regulamentos legais, permitindo a realização de atos desprovidos de condição específica. Isso reforça a convocação de pessoal sem perfil adequado para atuação na UCI, além de tornar viável a continuidade de ações ilícitas, pelo despreparo no acompanhamento e controle das atividades e das ações oriundas da gestão pública.

Diante disso, constatou-se que mesmo com a forte atuação do Tribunal de Contas do Estado de Rondônia no ambiente público municipal, ainda ocorre atos ilícitos resultantes de descuidos no controle interno.

Nesta pesquisa foram examinadas as legislações que tratam da institucionalização da unidade de controle interno nos Poderes Públicos Municipais, em particular os Poderes Executivo e Legislativo do Estado de Rondônia, tendo como amostra os 10 (dez) maiores municípios por porte populacional, com atenção especial para as abordagens relacionadas ao ponto cego da UCI.

Como este trabalho se limitou ao Estado de Rondônia, seria interessante a ampliação deste estudo, com o exame de regulamentos de outros Estados, fazendo comparativos e apresentando possíveis diferenças, consideradas em alguns casos promissoras, para o controle no ambiente público municipal.

\section{Referências:}

ANDRADE, N. A. Contabilidade pública na gestão municipal. 3 ed. -2 reimpr.- São Paulo: Atlas, 2008.

BRASIL. Constituição da República Federativa do Brasil: de 5 de outubro de 1988. $34^{\text {a }}$ ed. São Paulo: Atlas, 2011.

Instrução Normativa 01, 06 de abr. 2001. Disponível em:

http://www.cgu.gov.br/AreaAuditoriaFiscalizacao/Arquivos/AuditoriasAnuaisEPrestContas/I N_01_06042001.pdf Acesso em: 9dez2016.

CARNEIRO JUNIOR, E. da S.; OLIVEIRA, J. R. S. Falhas de controle interno nas contas municipais da microrregião de Feira de Santana apontadas pelo Tribunal de Contas dos Municípios da Bahia (2005/2009). 12 $^{\circ}$ Congresso USP de Controladoria e Contabilidade, 2012, São Paulo. Disponível em:

http://www.congressousp.fipecafi.org/web/artigos122012/573.pdf Acesso em: 27out2016. 
CENSO 2011. Instituto Brasileiro de Geografia e Estatística (IBGE). Estimativas da população brasileira com data de referência em $1^{\circ}$ de julho de 2011. Disponível em: http://www.ibge.gov.br/home/estatística/populacao/estimativa2011/estimativa.shtm Acesso em: 4jan2016.

CHU, R. A.; WOOD Jr., T. Cultura organizacional brasileira pós-globalização: global ou local? Revista de Administraçõ Pública. Rio de Janeiro, n. 42 (5)., p. 969-91. Set/Out, 2008. Disponível em: http://www.scielo.br/pdf/rap/v42n5/a08v42n5.pdf Acesso em: 23set2011.

DAVIS, M. D. ; BLASCHEK, J. R. de S. Deficiências dos Sistemas de Controle Interno Governamentais atuais em função da evolução da Economia. In: 6o Congresso USP de Controladoria e Contabilidade, 2006, São Paulo. 6o Congresso USP de Controladoria e Contabilidade. Disponível em: http://www.rio.rj.gov.br/dlstatic/10112/3268049/DLFE259741.pdf/0.2..pdf Acesso em: 14mar2016.

KLERING, L. R.; BERGUE, S. T.; SCHROEDER, C. da S.; PORSSE, M. de C. S.; STRANZ, E.; KRUEL, A. J. Competências, papéis e funções dos poderes municipais no contexto da administração pública contemporânea. Análise - A Revista Acadêmica da FACE. Porto Alegre, v. 22, n 1, p. 31-43, jan./jun. 2011. Disponível em: http://revistaseletronicas.pucrs.br/ojs/index.php/face/article/viewFile/9778/6701 Acesso em: 8nov2016.

LIMA, G. C. de. MIRANDA, L. C. Avaliação dos órgãos de controle interno nos municípios brasileiros: Análise a partir dos regulamentos legais. Dissertação de Mestrado do CCSA UFPE. 2012. Disponível em:

https://www.ufpe.br/ppgcontabeis/images/documentos/Dissertacoes/gleice\%20carvalho.pdf Acesso em: 2nov2016.

LIMA, G. C. de; MIRANDA, L. C. VASCONCELOS, M. T. de C. OLIVEIRA, R. R. Avaliação das normas editadas pelos Tribunais de Contas Brasileiros para orientar os Poderes Municipais na institucionalização dos sistemas de controle interno. Revista Registro Contábil - UFAL. Maceió/Al, RECONT: 2014. Disponível em: http://www.seer.ufal.br/index.php/registrocontabil/article/view/20/pdf_13 Acesso em: 14 mar2016.

LOPES, A. Prefeito preso chefiava grupo que desviou R $\$ 5$ milhões em Vilhena. Telejornal Globo. 2016. Disponível em: http://g1.globo.com/ro/vilhena-e-cone-

sul/noticia/2016/11/prefeito-preso-chefiava-grupo-que-desviou-r-5-mi-em-vilhena-diz-pf.html Acesso em: 11nov2016.

MORELO, N. The importance of internal control in the brazilian public administration. The George Washington University - School of Business and Public Management. Minerva Program Spring, abril/2011. Disponível em:

http://www2.aneel.gov.br/biblioteca/trabalhos/trabalhos/Artigo_Natan_Morelo.pdf Acesso em 14 mar2016.

MORENO, G. C. de L.; MIRANDA, L. C. Avaliação dos órgãos de controle interno nos Poderes Municipais Brasileiros: Análise a partir dos regulamentos legais. Revista Gestão \& 
Políticas Públicas - RGPP. São Paulo: RGPP, 2013. Disponível em: http://each.uspnet.usp.br/rgpp/index.php/rgpp/article/view/96/140 Acesso em: 12mar2016.

MPE - ES. Primos do prefeito de Itapemirim negam participação em esquema. 2015. Disponível em: http://g1.globo.com/espirito-santo/noticia/2015/12/primos-do-prefeito-deitapemirim-negam-participacao-em-esquema.html Acesso em: 12fev2016.

MPE- MA. Prefeita de Bom Jardim é investigada por desvio de verbas da educação. 2015. Disponível em: http://g1.globo.com/ma/maranhao/noticia/2015/08/prefeita-de-bom-jardim-einvestigada-por-desvios-de-verbas-da-educacao.html Acesso em: 14jan2016.

OLIVEIRA, E. P. de; LIMMA, F. A.; SILVA NETO, J. M. da; PEREIRA, S. A. O controle interno como mecanismo de auxílio na eficiência da gestão municipal. Revista Gestão e Controle/ Tribunal de Contas do Estado de Rondônia. Ano 1, n. 1 (jan/jun 2013). Porto Velho: TCE-RO, 2013.

SILVA, L. M. da. A Importância da Auditoria Forense na Formação dos Contadores. Educação Contábil: tópicos de ensino e pesquisa. Jorge Lopes, José Francisco Ribeiro Filho e Marcleide Pederneiras (organizadores). São Paulo: Atlas, 2008.

CARNEIRO, A. de F.; SILVA NETO, J. M. da. Competências essenciais dos profissionais contábeis em face da nova contabilidade pública sob a perspectiva dos contadores de Rondônia. Revista Gestão, Finanças e Contabilidade, v. 5, n. 3, 2015. Disponível em: http://www.revistas.uneb.br/index.php/financ/article/view/959/899 Acesso em: 9dez2016.

TCE-RO. Decisão Normativa n. 002/2016/TCE-RO. Tribunal de Contas do Estado de Rondônia. Disponível em: http://www.tce.ro.gov.br/tribunal/legislacao/arquivos/DeNo-0022016.pdf Acesso em: $1^{\circ}$ out 2016.

TCE-RS. Ex-presidente da Câmara de Vereadores de Tramandaí tem contas regulares com ressalvas. Disponível em: http://www1.tce.rs.gov.br/portal/page/portal/tcers/administracao/gerenciador_de_conteudo/no $\underline{\text { ticias/Ex- }}$ presidente $\% 20 \mathrm{da} \% 20 \mathrm{C} \% \mathrm{E} 2 \mathrm{mara} \% 20 \mathrm{de} \% 20$ Vereadores $\% 20 \mathrm{de} \% 20$ Tramanda $\%$ ED $\% 20$ tem $\%$ 20contas\%20regulares\%20com\%20ressalvas Acesso em: $20 \mathrm{jan} 2016$. 